\title{
THE EUROSIDA STUDY: REGIONAL DIFFERENCES IN THE HIV-1 EPIDEMIC AND TREATMENT RESPONSE TO ANTIRETROVIRAL THERAPY AMONG HIV-INFECTED PATIENTS ACROSS EUROPE - A REVIEW OF PUBLISHED RESULTS
}

\author{
Daria Podlekareva ${ }^{1}$, Wendy Bannister ${ }^{2}$, Amanda Mocroft ${ }^{2}$, Ludmila Abrosimova ${ }^{3}$, Igor Karpov, \\ Jens D. Lundgren ${ }^{1}$, Ole Kirk ${ }^{1}$ for the EuroSIDA study group \\ ${ }^{1}$ Copenhagen HIV Programme, University of Copenhagen, Denmark \\ ${ }^{2}$ Royal Free and University College Medical School, London, United Kingdom \\ ${ }^{3}$ Botkin Infectious Diseases Hospital, St. Petersburg, the Russian Federation \\ ${ }^{4}$ Minsk State Medical University, Belarus
}

\begin{abstract}
SUMMARY
EuroSIDA is a pan-European observational study that follows 14,265 HIV-infected patients from 31 European countries, Israel and Argentina, of which 2,560 are patients from eastern Europe (EE). The study group has performed several analyses addressing regional differences in the HIV-epidemic across Europe, where all countries were divided into five regions: south, west central, north, east central Europe and EE. Significant regional differences in patients' characteristics and pattern of AIDS diagnoses were documented. More patients from EE were diagnosed with tuberculosis compared to other regions. Significantly fewer HIV-infected patients in EE, who fulfilled the criteria for starting combination antiretroviral therapy (CART), actually received cART as compared with other regions of Europe. Those, receiving cART in EE had a lower initial virologic response rate irrespectively of the regimen used, although it has improved within years. Besides, treatment failure was more common in this region. Thus, improvements in the clinical management of HIV patients in EE are urgently needed. Strategies include creating scientific collaborations for HIV clinicians as well as teaching clinicians about the most advanced HIV management at clinically oriented courses held in eastern Europe.
\end{abstract}

Key words: Eastern Europe, EuroSIDA study, HIV-infection management, collaboration

Address for correspondence: D. Podlekareva, Copenhagen HIV Programme, University of Copenhagen, The Panum Institute/Building 21.1, Blegdamsvej 3B, 2200 Copenhagen N, Denmark. E-mail: dpo@cphiv.dk

\section{INTRODUCTION}

The EuroSIDA study was initiated in 1994 as a European multinational observational cohort of HIV-1 infected people across Europe. It currently includes more than 14,200 patients followed in 93 hospitals in 31 European countries as well as in Israel and Argentina. The main objectives of the study are to follow the clinical long-term prognosis for HIV-1 infected people and to assess the impact of antiretroviral drugs on the outcome of the general HIV-1 population in Europe. Since 1996, the study has published more than 85 articles in peer-reviewed journals. Being a multinational, pan-European cohort, the EuroSIDA study is in a unique position for analysing regional differences in various aspects of the HIV-1 epidemic and response to antiretroviral therapy (ART) across the European continent. Over the last five years there has been a growing interest in the situation in Eastern Europe (EE). Since 1999, the EuroSIDA study has recruited patients in the eastern part of Europe: initially in the Czech Republic,
Hungary and Poland, and later also in Estonia, Latvia, Lithuania, Romania, Slovakia and Ukraine. In late 2003, clinics in Belarus, Russia and Serbia and in 2006 Bulgaria and Croatia joined the study. The first results from the EuroSIDA study on EE emerged in 2004 - after a significant number of patients were recruited into the study and follow-up had accumulated.

It is well known that the HIV-1 epidemic shows major differences across Europe (1). However, no studies have previously compared the clinical characteristics of patients in regions of Europe. To our knowledge, there are no other existing cohorts of HIV-1 infected people in Eastern Europe. Thus, the EuroSIDA study has a unique opportunity of analysing the HIV-1 epidemic in this region and comparing these results with those obtained in Western Europe. In particular, the strength of the EuroSIDA study is in providing a prospective collection of individual-based clinical data compared with population-based epidemiological data (1). 


\section{EUROSIDA STUDY: DESIGN AND METHODS}

EuroSIDA is a prospective observational cohort study of 14,265 HIV-1 infected patients from 93 hospitals in 31 European countries, Israel and Argentina, coordinated by the Copenhagen HIV Programme (CHIP) (2). Currently, there are 9,000 patients under active follow-up. Patients eligible for enrolment are consecutive HIV-1 infected people aged 16 and older under active follow-up within a clinic and with a pre-booked clinic appointment (i.e. unselected patients). Study details have been published elsewhere (3). In total, there have been seven cohorts of patients recruited into the study since 1994. Cohort I began in May 1994, enrolling patients until a predefined number was reached from each centre, totaling 3,116. Cohort II enrolled 1,365 patients in Autumn 1995/Spring 1996; cohort III, a further 2,843 during 1997; cohort IV enrolled 1,225 in 1999; cohort V, 1,258 patients in Autumn 2001/ Spring 2002; cohort VI enrolled 2,121 patients during Autumn 2003/Spring 2004; and cohort VII completed enrolment of 2,337 patients in 2007. During 2008, EuroSIDA is recruiting an additional 2,500 patients into cohort VIII. Patients' information is collected on a standardized data collection form at enrolment and every six months thereafter. At each visit, details on all CD4 counts and viral loads measured since the last follow-up are collected. The dates of starting and stopping each antiretroviral drug are recorded, as is the use of prophylactic drugs against opportunistic infections.

Dates of diagnosis of all AIDS-defining illnesses, including those made subsequent to the initial diagnosis, are also recorded using the 1993 clinical definition of AIDS from the US Centers for Disease Control (4). New questions have been added to the form as concern of specific clinical problems have arisen (e.g. severe liver disease, cardiovascular disease, pancreatitis and end-stage renal disease). Complete information about the data items collected is available at www.cphiv.dk on the follow-up form. Members of the coordinating office visit all centres to facilitate correct patient selection and to verify that accurate data are supplied by checking the information provided on all clinical events as well as a randomly selected subgroup of the patients.
For regional analysis, all patients are divided into five regions according to the place of residence ${ }^{1}$ :

- South (SE): Spain, Portugal, Italy, Greece, Israel, Argentina;

- West Central (WC): France, Belgium, South Germany, Luxembourg, Switzerland, Austria;

- North (NE): United Kingdom, Ireland, the Netherlands, North Germany, Denmark, Sweden, Norway, Finland;

- East Central (EC): Poland, the Czech Republic, Slovakia, Hungary, Romania, Serbia, Bulgaria, Croatia;

- East (EE): Estonia, Latvia, Lithuania, Belarus, Ukraine, the Russian Federation.

\section{HIV-EPIDEMIC: REGIONAL DIFFERENCES IN PA- TIENTS' CHARACTERISTICS AND AIDS-DEFINING DIAGNOSES}

As follow-up accumulated on patients followed in EE, it is now possible to make regional comparisons showing the patterns of the HIV-1 epidemic in this region. The results of this analysis were presented in 2004 at the Seventh International Congress on Drug Therapy in HIV Infection in Glasgow (5).

7,104 patients were included in this analysis, aiming to compare characteristics of HIV-1 patients studied in different regions of Europe and to assess any regional differences in the use of combination antiretroviral therapy (cART) (Table 1). Compared to the other regions, HIV-1 infected patients in EC and EE were younger, with a higher percentage of women, and the most common HIV transmission category in these regions was injecting drug use (IDU). A high percentage of these patients were coinfected with hepatitis $\mathrm{C}$ virus (HCV).

A shorter duration of known HIV infection, a higher nadir CD4 count and a lower percentage with an AIDS diagnosis in EC and EE reflected a more recent epidemic in these regions (Table 1).

Significantly fewer patients in EE received cART in late 2003/ early 2004 (Table 2), and this finding remained after adjusting for other factors influencing the initiation of cART, such as HIV

Table 1. Characteristics of patients followed in the EuroSIDA study, September 2003

\begin{tabular}{|c|c|c|c|c|c|c|}
\hline & $\begin{array}{c}\text { SE } \\
n=1888\end{array}$ & $\begin{array}{c}\text { WC } \\
n=1911\end{array}$ & $\begin{array}{c}\mathrm{NE} \\
\mathrm{n}=1974\end{array}$ & $\begin{array}{c}E C \\
n=890\end{array}$ & $\begin{array}{c}E E \\
n=441\end{array}$ & p-value \\
\hline Age, yrs; median (IQR) & $41(37-47)$ & $43(39-51)$ & $44(39-52)$ & $36(31-44)$ & $30(24-39)$ & $<0.001$ \\
\hline Female, \% & 28 & 23 & 18 & 30 & 31 & $<0.001$ \\
\hline IVDU, \% & 29 & 14 & 11 & 30 & 51 & $<0.001$ \\
\hline $\mathrm{HCV}, \%$ & 30 & 17.5 & 13 & 34 & 33 & $<0.001$ \\
\hline Time from HIV diagnosis, mths; median (IQR) & $122(78-164)$ & $134(96-177)$ & $136(96-186)$ & $75(39-119)$ & $32(18-53)$ & $<0.001$ \\
\hline on cART, \% & 77 & 80 & 84 & 78 & 30 & $<0.001$ \\
\hline CD4 count cells/mm3; median (IQR) & $459(291-679)$ & $429(281-601)$ & $449(300-620)$ & $484(297-659)$ & 337 (185-593) & $<0.001$ \\
\hline Nadir CD4 count cells/mm; median (IQR) & $150(57-263)$ & $131(49-229)$ & $113(42-200)$ & $144(65-270)$ & $270(131-476)$ & $<0.001$ \\
\hline HIV-RNA copies/ml; median (IQR) & $1.9(1.7-3.3)$ & $1.7(1.7-2.7)$ & $1.7(1.3-2.0)$ & $2.6(1.7-2.7)$ & $2.7(2.3-4.9)$ & $<0.001$ \\
\hline AIDS diagnosis, $n$ (\%) & $509(27)$ & $588(31)$ & $684(35)$ & $214(24)$ & $117(26.5)$ & $<0.001$ \\
\hline Pts with pulmonary tuberculosis, $n(\%)$ & $74(14.5)$ & $66(11)$ & $63(9)$ & $42(20)$ & $20(17)$ & $<0.001$ \\
\hline
\end{tabular}

\footnotetext{
${ }^{1}$ This is the current regional distribution, used since 2007. At the time of analysis described here, Serbia was in SE while Bulgaria, Croatia and Finland were not yet part of the study.
} 
Table 2. Odds ratio of EuroSIDA patients being on CART, September 2003

\begin{tabular}{|c|c|c|c|c|c|c|c|c|}
\hline & \multicolumn{3}{|c|}{ Univariable } & \multicolumn{3}{|c|}{ Multivariable } & \multirow{2}{*}{$\begin{array}{c}\text { Total } \\
\text { patients }\end{array}$} & \multirow{2}{*}{$\begin{array}{c}\% \text { on } \\
\text { HAART }\end{array}$} \\
\hline & OR & $95 \% \mathrm{Cl}$ & $P$ & OR & $95 \% \mathrm{Cl}$ & $\mathbf{P}$ & & \\
\hline South & 0.64 & $(0.55,0.76)$ & $<0.001$ & 0.96 & $(0.8,1.14)$ & 0.616 & 1,888 & $77 \%$ \\
\hline West Central & 0.74 & $(0.63,0.88)$ & $<0.001$ & 1.05 & $(0.87,1.25)$ & 0.622 & 1,911 & $80 \%$ \\
\hline North & 1.00 & & & 1.00 & & & 1,974 & $84 \%$ \\
\hline East Central & 0.68 & $(0.55,0.83)$ & $<0.001$ & 1.24 & $(0.99,1.55)$ & 0.066 & 890 & $78 \%$ \\
\hline East & 0.08 & $(0.07,0.11)$ & $<0.001$ & 0.27 & $(0.2,0.36)$ & $<0.001$ & 441 & $30 \%$ \\
\hline
\end{tabular}

Adjusted for region, HIV exposure, age, AIDS diagnosis, HBV/HCV coinfection, CD4 cell count and HIV-RNA

exposure group, age, AIDS diagnosis, HCV coinfection, CD4 counts and viral load.

In addition, there were several regional differences in the pattern of AIDS events (Table 1). Of special interest was the fact that the percentage of patients with pulmonary tuberculosis (TB) among all patients with an AIDS diagnosis was higher in the EE, EC and SE compared to the NE and WC. Regional differences in the prevalence and patterns of AIDS-defining events (ADE) were further explored with a special focus on EE (6). It was shown that the percentage of patients developing an ADE in EE was as expected in the lower range due to the recent epidemic onset (\% of patients with ADE: 17, 17, 20, 9, 12 in SE, WC, NE, EC and EE respectively). At the same time, it was not low enough to be ignored. In total, 1,136 patients out of 6,918 had experienced at least one ADE (Fig. 1). This analysis was restricted to the period between one year prior to enrolment to EuroSIDA and April 2004.

The regional differences observed at that time included a higher proportion of Kaposi's sarcoma (KS) in SE, WC and NE ( $p=0.001)$. A higher prevalence of KS primarily in Northern but also in Western and Southern regions was probably explained by pronounced regional differences in the transmission category of the HIV-1 population. A higher proportion of patients in NE were infected by homosexual contact, and KS is caused by human herpes virus type 8 , which is highly prevalent in homosexual populations and transmitted by homosexual contact (7). Cytomegalovirus infec-

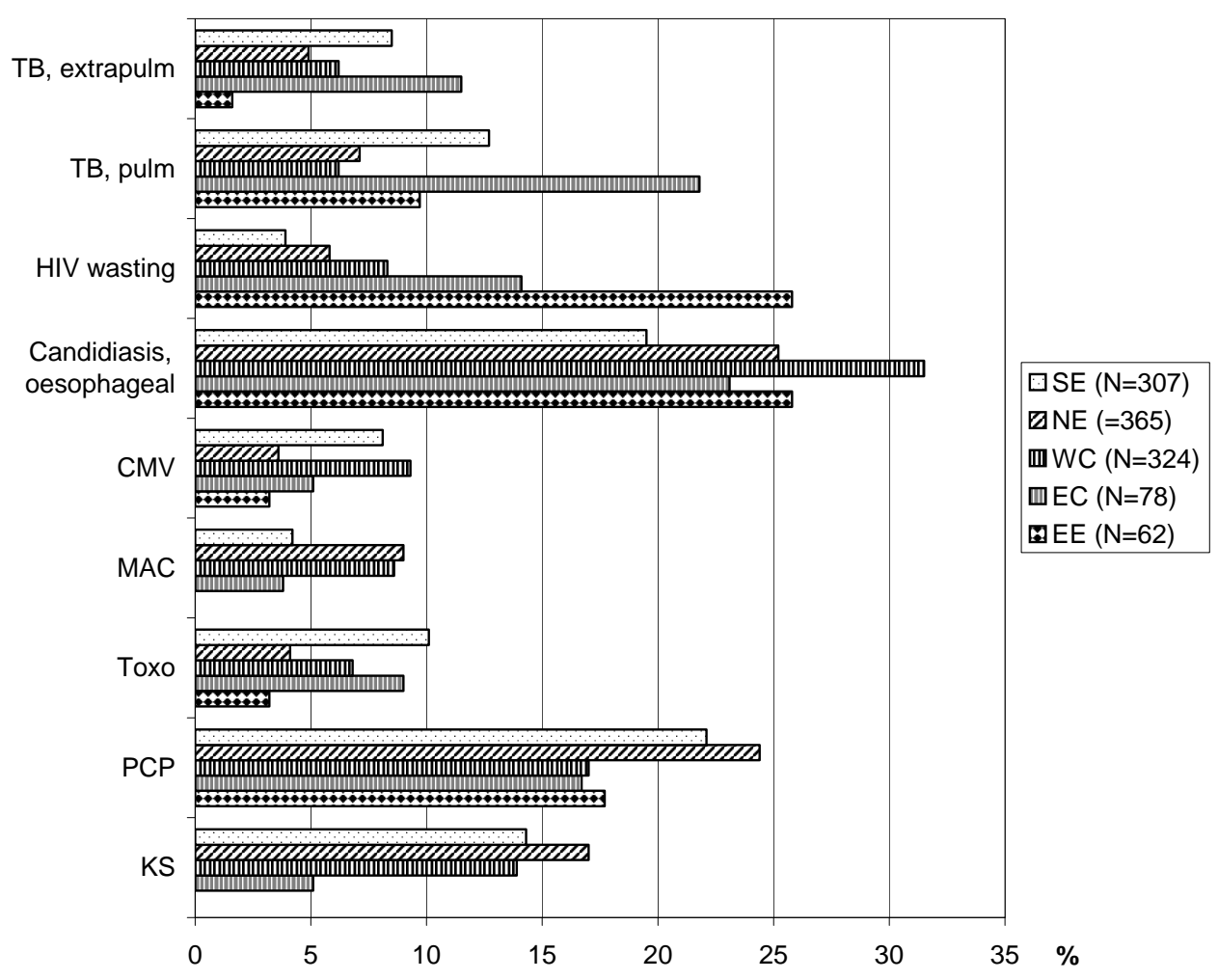

Fig. 1. AIDS-defining diagnoses in EuroSIDA patients according to the region of Europe, September 2004.

TB, extrapulm - extrapulmonary tuberculosis, $p=0.057$, TB, pulm - pulmonary tuberculosis, $p<0.001$, HIV wasting, $p<0.001$, oesophageal candidiasis, $p=0.016, C M V-$ cytomegalovirus infection, $p=0.018$, MAC - Mycobacterium avium complex, $p=0.009$, Toxo - brain toxoplasmosis, $p=0.023, P C P-$ Pneumocystis jiroveci pneumonia, $p=0.124, K S-K a p o s i$ sarcoma, $p=0.001$. 
tion, disseminated Mycobacterium avium complex infection and cerebral toxoplasmosis are known to almost exclusively occur during pronounced immunodeficiency (8), which explains why these infections contributed to higher proportion in NE and WE regions. The relatively late onset of the HIV-1 epidemic in EE and the relatively low prevalence of profound immunodeficiency in this region at that time point is the likely reason for the very few cases of these diseases in EE. Another suggestion could be diagnostics issues. A high prevalence of PCP and oesophageal candidiasis in EE can partially be explained by the fact that these diseases develop at relatively high CD4 cell counts and have more simple diagnostics procedures. Of note though is a high prevalence of HIV wasting syndrome observed in EE at the time of this analysis, while pulmonary Mycobacterium tuberculosis (TB) infections were more prevalent in EC. The likely explanation can be under-diagnosis of TB (and other ADEs, requiring complex diagnostic procedures) and misclassification of HIV wasting syndrome. This diagnosis is made by the exclusion of others and therefore requires thorough examination for the elimination of a variety of other severe HIVrelated and non-HIV-related diseases.

There were no significant differences observed between regions in the level of CD4 cells at the time of first ADE ( $p=0.132)$. However, there was a trend for HIV wasting diagnosis to be made at a higher CD4 cell count in EE (median CD4 283 cells $/ \mathrm{mm}^{3}$ ) than in other regions (median CD4 67, 150, 80, and 80 cells $/ \mathrm{mm}^{3}$ in SE, WC, NE and CE respectively), $p=0.18$.

Analyses also revealed a considerably higher percentage of patients in EE who were naive to ART at the time of AIDS diagnosis. This was particularly true for patients with such diagnoses as oesophageal candidiasis, HIV wasting and TB (81\%, $88 \%$ and $71 \%$ of patients were ART-naive for each diagnosis respectively).

\section{VIROLOGIC RESPONSE TO CART: REGIONAL CHANGES OVER TIME}

EuroSIDA has also investigated regional changes over time in virologic response to cART (9). 2,102 previously ART-naïve patients, who started cART between 1996 and 2004, were analysed. Patients were eligible for analysis if they had at least one year of follow-up after starting cART and with a baseline viral load (vL) $\geq 500$ copies/ml. cART was defined as at least 3 antiretroviral drugs including a protease inhibitor (PI), a non-nucleoside reverse transcriptase inhibitor (NNRTI) or abacavir and cART regimens were compared according to the initiation date, defined as early cART (1996-1997), mid cART (1998-1999), and late cART (2000-2004). Countries from East Central Europe and Eastern Europe were combined in one region due to low number of patients starting cART in EE in this time period. Some regional differences in initial virologic response to cART were observed. EE was characterised by a lower initial virologic response rate. These differences remained after adjustment and could not be explained by different cART regimens used across Europe. Sixty per cent of 2,102 patients achieved virologic suppression at the first vL measurement in a 6 to12 months period after cART initiation. Response rates were similar across regions (57\%, 61\%, 63\% and 58\% for SE, WC, NE and EE respectively; $p=0.091$ ); however, a significant overall increase in response rate was observed, as well as within each region separately $(\mathrm{p}<0.001)$. The most noticeable increase was in EE: from $20 \%$ in early cART to $63 \%$ in the late cART era. Adjusted odds ratios (OR) of virologic response in each period according to the region and in each region according to the period are presented in Figure 2. EE had the lowest odds of achieving virologic suppression in all three periods. However, this increased over time to become more consistent with the other regions.

The authors also observed a significant regional variation in the type of initial cART regimen in all three time periods; however, the magnitude of differences decreased over time. This suggests that treatment policies became more consistent throughout Europe as a result of the increasing widespread availability of antiretroviral drugs.

It is known that in Eastern Europe non-B HIV-1 subtypes are widespread (10) and this could at least partially explain the differences in virologic response. Therefore, a comparative analysis of virologic and immunological response to cART between patients infected with HIV-1 B and non-B subtypes across Europe was performed. The results showed that "after adjustment for potentially confounding variables, there was no evidence of significant differences in virologic or immunological response to cART" between patients infected with different HIV-1 subtypes (10).
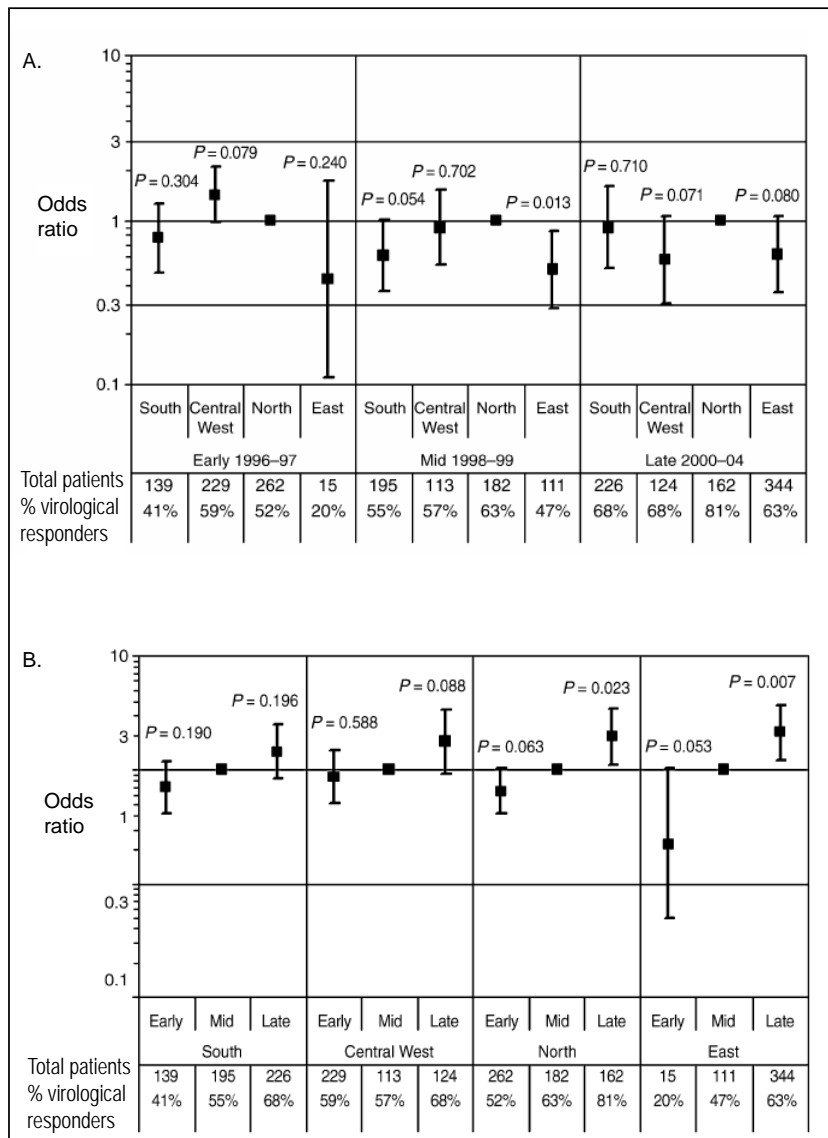

Fig. 2. Adjusted odds ratios of virologic response (viral load $G$ 500 copies $/ \mathrm{ml}$ ) after starting cART in: A. each period according to region and $B$. each region according to period (missing viral load = virologic failure). Reprinted from Bannister WP et al. J Acquir Immune Defic Syndr. 2006;42(2):229-237. 
TRIPLE CLASS FAILURE: REGIONAL DIFFERENCES

One of the latest EuroSIDA publications is dedicated to the investigation of regional differences in the risk of triple class failure (TCF) in European patients starting cART after 1 January 1999 (11). TCF was defined as the failure of each of the three main classes of ARVs (NRTI, NNRTI and PI) with a vL of $>1,000$ copies/ml for at least four months. The study of 1,956 patients included in the analysis demonstrated a low incidence of TCF, which decreased over follow-up time from over 20/1,000 person years of follow-up (PYFU) for patients under follow-up during 2000-2003, to less than 10/1,000 PYFU for patients under followup during 2004 and 2005 ( $\mathrm{p}=0.014$ ). In a multivariate analysis of incidence rate ratios (IRRs) of TCF, patients from EE had a significantly higher incidence of TCF compared with patients from Southern Europe (IRR 3.05; 95\% CI 1.36-6.82; p=0.0067). The other regions of Europe were not significantly different from SE. Other factors significantly associated with TCF were prior ARV treatment (IRR 1.93; 95\% CI 1.16-3.20; $\mathrm{p}=0.011$ ) and starting cART with a single-PI-based regimen (IRR 0.33; 95\% CI 0.15-0.74; $\mathrm{p}=0.0072$ ). The latest could be explained by temporal changes in the cART regimens used.

The higher TCF rates in EE are consistent with a lower initial virologic response rates in this region, which was reported in the previous study (9).

\section{PERSPECTIVE ANALYSIS ON REGIONAL DIFFER- ENCES}

An ongoing EuroSIDA analysis is dedicated to the regional differences in the clinical management of HIV-1 infected patients across Europe (12). Compliance with current HIV-guidelines (in particular use of cART among patients with low CD4 cell count, regimen of cART used, frequency of monitoring, i.e. CD4 cell and VL measurements) and ability to maintain maximum virologic suppression in different European regions are assessed in this work.

\section{CONCLUSIONS}

EuroSIDA is one of the largest multicentre European prospective observational cohort studies and therefore has a unique position to analyse regional differences of various aspects of HIV-1 infection, both from clinical and epidemiological points of view. Within recent years, EuroSIDA has demonstrated substantial regional differences in demographic and clinical characteristics of HIV-1 infected patients in different regions of Europe. Our data support the general knowledge of a more recent HIV epidemic in Eastern Europe (1). The low usage of cART in Eastern Europe compared with the other European regions is of particular concern. Lower initial virologic response to cART and higher rates of triple class failure in this region have been reported. Another alarming fact is that a high proportion of AIDS patients in East Central and Eastern Europe have been diagnosed with pulmonary tuberculosis. As the HIV-1 epidemic matures in Eastern Europe and more profound immune deficiency develops, the incidence of TB as well as other ADEs may well increase in the coming years (13). Although access to cART has significantly improved within the last years, the need for treatment is growing much faster in countries of the former USSR (14). The rapidly increasing incidence of TB along with a high prevalence of multi-drug resistant mycobacterium in the general population stresses the need to focus future research efforts on this matter (15). A separate project dedicated to investigating clinical issues related to HIV/TB coinfection has been initiated by the EuroSIDA collaboration and the first data has already been presented (16).

Suboptimal utilisation of health care may lead to inferior clinical prognosis. Thus, there is an urgent need for not only improving access to cART, but also to provide a continuous education to health care professionals on optimal use of cART. The HIV-1 population in Eastern Europe is predominantly injecting drug users with a lower access to cART as compared to other groups (17). Therefore, while treatment is scaling-up, resources should be dedicated to IDUs, the largest risk group for HIV in this region, including ensuring better access to cART and other components of the clinical management in accordance with the international guidelines.

Under the 6th Framework grant application to the European Commission, EuroSIDA committed to continue expanding in Eastern Europe and to further increase the number of patients and clinical sites in this region. The EuroSIDA study actively participates in continued training and education of clinical colleagues from Eastern Europe by organising clinical and statistical courses; actively encouraging clinicians to take part in scientific projects; and providing training in data collection and quality assurance. Participation in EuroSIDA also assists clinicians in building skills that are relevant for a proper data collection and good clinical practice. This can lead to participation in randomised clinical trials (several sites from EuroSIDA were also included in the SMART ${ }^{2}$ study). EuroSIDA is also dedicated to educate colleagues from Eastern Europe in the clinical aspects of HIV infection and basic statistics.

In summary, EuroSIDA research contributes to the identification of problems and areas with suboptimal management of clinical issues, thus serving for the standardisation and optimisation of the clinical management of HIV-1 infected patients both within and outside Europe. Unless access to and usage of cART and other HIV-related health care interventions in Eastern Europe are improved, it is likely that the differences will translate into even more pronounced differences in mortality and morbidity in HIV-1 patients in Eastern and Western Europe in the coming years.

\section{Acknowledgements}

The European Commission BIOMED 1 (CT94-1637), BIOMED 2 (CT972713), the 5th Framework (QLK2-2000-00773) and the 6th Framework (LSHP-CT-2006-018632) programmes were the primary sponsors of the study. Unrestricted grants were also provided by Bristol-Myers Squibb, GlaxoSmithKline, Roche, Gilead, Pfizer, Merck and Co., Tibotec and Boehringer-Ingelheim. The participation of centres from Switzerland was supported by a grant from the Swiss Federal Office for Education and Science.

${ }^{2}$ A Large, Simple Trial Comparing Two Strategies for Management of Anti-Retroviral Therapy (The SMART Study) 


\section{Appendix A}

The multicenter study group on EuroSIDA was constituted as follows (national co-ordinators in parentheses).

Argentina: (M Losso), A Duran, Hospital JM Ramos Mejia, Buenos Aires. Austria: (N Vetter) Pulmologisches Zentrum der Stadt Wien, Vienna. Belarus: (I Karpov), A Vassilenko, Belarus State Medical University, Minsk, VM Mitsura, Gomel State Medical University, Gomel; O Suetnov, Regional AIDS Centre, Svetlogorsk. Belgium: (N Clumeck) S De Wit, B Poll, Saint-Pierre Hospital, Brussels; R Colebunders, Institute of Tropical Medicine, Antwerp Bulgaria: K Kostov, Infectious Diseases Hospital, Sofia. Croatia; J Begovac, University Hospital of Infectious Diseases, Zagreb. Czech Republic: (L Machala) H Rozsypal, Faculty Hospital Bulovka, Prague; D Sedláček, Charles University Hospital, Plzeň. Denmark: (J Nielsen) J Lundgren, T Benfield, O Kirk, Hvidovre Hospital, Copenhagen; J Gerstoft, T Katzenstein, A-B E Hansen, P Skinhøj, Rigshospitalet, Copenhagen; C Pedersen, Odense University Hospital, Odense, L Oestergaard, Skejby Hospital, Aarhus. Estonia: (K Zilmer) West-Tallinn Central Hospital, Tallinn, Jelena Smidt, Nakkusosakond Siseklinik, Kohtla-Järve. Finland: (M Ristola), Helsinki University Central Hospital, Helsinki. France: (C Katlama) Hôpital de la Pitié-Salpétičre, Paris; J-P Viard, Hôpital Necker-Enfants Malades, Paris; P-M Girard, Hospital Saint-Antoine, Paris; JM Livrozet, Hôpital Edouard Herriot, Lyon; P Vanhems, University Claude Bernard, Lyon; C Pradier, Hôpital de l'Archet, Nice; F Dabis, D Neau, Unité INSERM, Bordeaux. Germany: (J Rockstroh) Universitäts Klinik Bonn; R Schmidt, Medizinische Hochschule Hannover; J van Lunzen, O Degen, University Medical Center Hamburg-Eppendorf, Infectious Diseases Unit, Hamburg; HJ Stellbrink, IPM Study Center, Hamburg; S Staszewski, JW Goethe University Hospital, Frankfurt; J Bogner, Medizinische Poliklinik, Munich; G. Fätkenheuer, Universität Köln, Cologne. Greece: (J Kosmidis) P Gargalianos, G Xylomenos, J Perdios, Athens General Hospital; G Panos, A Filandras, E Karabatsaki, 1st IKA Hospital; H Sambattakou, Ippokration Genereal Hospital, Athens. Hungary: (D Banhegyi) Szent Lásló Hospital, Budapest. Ireland: (F Mulcahy) St. James’s Hospital, Dublin. Israel: (I Yust) D Turner, M Burke, Ichilov Hospital, Tel Aviv; S Pollack, G Hassoun, Rambam Medical Center, Haifa; S Maayan, Hadassah University Hospital, Jerusalem. Italy: (A Chiesi) Istituto Superiore di Sanitŕ, Rome; R Esposito, I Mazeu, C Mussini, Universitŕ Modena, Modena; C Arici, Ospedale Riuniti, Bergamo; R Pristera, Ospedale Generale Regionale, Bolzano; F Mazzotta, A Gabbuti, Ospedale S Maria Annunziata, Firenze; V Vullo, M Lichtner, University di Roma la Sapienza, Rome; A Chirianni, E Montesarchio, M Gargiulo, Presidio Ospedaliero AD Cotugno, Monaldi Hospital, Napoli; G Antonucci, F Iacomi, P Narciso, C Vlassi, M Zaccarelli, Istituto Nazionale Malattie Infettive Lazzaro Spallanzani, Rome; A Lazzarin, R Finazzi, Ospedale San Raffaele, Milan; M Galli, A Ridolfo, Osp. L. Sacco, Milan; A d'Arminio Monforte, Istituto Di Clinica Malattie Infettive e Tropicale, Milan. Latvia: (B Rozentale) P Aldins, Infectology Centre of Latvia, Riga. Lithuania: (S Chaplinskas) Lithuanian AIDS Centre, Vilnius. Luxembourg: (R Hemmer), T Staub, Centre Hospitalier, Luxembourg. Netherlands: (P Reiss) Academisch Medisch Centrum bij de Universiteit van Amsterdam, Amsterdam. Norway: (J Bruun) A Maeland, V Ormaasen, Ullevíl Hospital, Oslo. Poland: (B Knysz) J Gasiorowski, Medical University, Wroclaw; A Horban, Centrum Diagnostyki i Terapii AIDS, Warsaw; D Prokopowicz, A Wiercinska-Drapalo, Medical University, Bialystok; A Boron-Kaczmarska, M Pynka, Medical Univesity, Szczecin; M Beniowski, E Mularska, Osrodek Diagnostyki i Terapii AIDS, Chorzow; H Trocha, Medical University, Gdansk. Portugal: (F Antunes) E Valadas, Hospital Santa Maria, Lisbon; K Mansinho, Hospital de Egas Moniz, Lisbon; F Maltez, Hospital Curry Cabral, Lisbon. Romania: (D Duiculescu) Spitalul de Boli Infectioase si Tropicale: Dr. Victor Babes, Bucarest. Russia: (A Rakhmanova), Medical Academy Botkin Hospital, St Petersburg; E Vinogradova, St Petersburg AIDS Centre, St Peterburg; S Buzunova, Novgorod Centre for AIDS, Novgorod. Serbia: (D Jevtovic), The Institute for Infectious and Tropical Diseases, Belgrade. Slovakia: (M Mokráš) D Staneková, Dérer Hospital, Bratislava. Spain: (J González-Lahoz) V Soriano, L Martin-Carbonero, P Labarga, Hospital Carlos III, Madrid; B Clotet, A Jou, J Conejero, C Tural, Hospital Germans Trias i Pujol, Badalona; JM Gatell, JM Miró, Hospital Clinic i Provincial, Barcelona; P Domingo, M Gutierrez, G Mateo, MA Sambeat, Hospital
Sant Pau, Barcelona. Sweden: (A Karlsson), Karolinska University Hospital, Stockholm; PO Persson, Karolinska University Hospital, Huddinge; L Flamholc, Malmö University Hospital, Malmö. Switzerland: (B Ledergerber) R Weber, University Hospital, Zürich; P Francioli, M Cavassini, Centre Hospitalier Universitaire Vaudois, Lausanne; B Hirschel, E Boffi, Hospital Cantonal Universitaire de Geneve, Geneve; H Furrer, Inselspital Bern, Bern; M Battegay, L Elzi, University Hospital Basel. Ukraine: (E Kravchenko) N Chentsova, Kiev Centre for AIDS, Kiev. United Kingdom: (S Barton) St. Stephen's Clinic, Chelsea and Westminster Hospital, London; AM Johnson, D Mercey, Royal Free and University College London Medical School, London (University College Campus); A Phillips, MA Johnson, A Mocroft, Royal Free and University College Medical School, London (Royal Free Campus); M Murphy, Medical College of Saint Bartholomew's Hospital, London; J Weber, G Scullard, Imperial College School of Medicine at St. Mary's, London; M Fisher, Royal Sussex County Hospital, Brighton; R Brettle, Western General Hospital, Edinburgh.

Virology group: B Clotet (Central Coordinators) plus ad hoc virologists from participating sites in the EuroSIDA Study.

Steering Committee: F Antunes, B Clotet, D Duiculescu, J Gatell, B Gazzard, A Horban, A Karlsson, C Katlama, B Ledergerber (Chair), A D’Arminio Montforte, A Phillips, A Rakhmanova, P Reiss (Vice-Chair), J Rockstroh.

Coordinating Centre Staff: J Lundgren (project leader), O Kirk, A Mocroft, N Friis-Møller, A Cozzi-Lepri, W Bannister, M Ellefson, A Borch, D Podlekareva, J Kjær, L Peters, J Reekie.

\section{REFERENCES}

1. Hamers FF, Downs AM. HIV in central and eastern Europe. Lancet. 2003 Mar 22;361(9362):1035-44.

2. Oancea C, Mollerup D, Nielsen M, Kirk O, editors. EuroSIDA: a multicentre study. Tracking HIV/AIDS across Europe 2003. Hvidovre: Copenhagen HIV Programme; 2008.

3. Mocroft A, Ledergerber B, Katlama C, Kirk O, Reiss P, d'Arminio Monforte A, et al; EuroSIDA study group. Decline in the AIDS and death rates in the EuroSIDA study: an observational study. Lancet. $2003 \mathrm{Jul}$ 5;362(9377):22-9.

4. Centers for Disease Control. 1993 revised classification system for HIV infection and expanded surveillance case definition for AIDS among adolescents and adults. MMWR Recomm Rep. 1992 Dec 18;41(RR17):1-19.

5. Podlekareva D, Bannister W, Viksna L, Mocroft A, Knysz B, Reiss P, et al. HIV-patients across Europe: regional differences in patient characteristics. In: Seventh International Congress on Drug Therapy in HIV Infection; 2004 Nov 14-18; Glasgow. Glasgow: Clinical Care Options; 2004. p. 33-4. Abstract P-67.

6. Podlekareva D, Bannister W, Viksna L, Mocroft A, Knysz B, Reiss P, et al. HIV-patients across Europe: regional differences in patient characteristics and AIDS diagnoses. In:15th European Congress of Clinical Microbiology and Infectious Diseases; 2005 Apr 2-5; Copenhagen. Copenhagen: ECCMID; 2005. p. 52-3. Abstract O-217.

7. Blaxhult A, Fox Z, Colebunders R, Francioli P, Ben-Ishai Z, Fätkenheuer G, et al; EuroSIDA Study Group. Regional and temporal changes in AIDS in Europe before HAART. Epidemiol Infect. 2002 Dec;129(3):565-76.

8. Mocroft A, Youle M, Phillips AN, Halai R, Easterbrook P, Johnson MA, et al; Royal Free/Chelsea and Westminster Hospitals Collaborative Group. The incidence of AIDS-defining illnesses in 4883 patients with human immunodeficiency virus infection. Arch Intern Med. 1998 Mar 9;158(5):491-7.

9. Bannister WP, Kirk O, Gatell JM, Knysz B, Viard JP, Mens H, et al; EuroSIDA Study Group. Regional changes over time in initial virologic response rates to combination antiretroviral therapy across Europe. J Acquir Immune Defic Syndr. 2006 Jun;42(2):229-37.

10. Bannister WP, Ruiz L, Loveday C, Vella S, Zilmer K, Kjaer J, et al; EuroSIDA Study Group. HIV-1 subtypes and response to combination antiretroviral therapy in Europe. Antivir Ther. 2006;11(6):707-15.

11. Mocroft A, Horban A, Clotet B, d'Arminio Monforte A, Bogner JR, Aldins P, et al; EuroSIDA Study Group. Regional differences in the risk of triple class failure in European patients starting combination antiretroviral therapy after 1 January 1999. HIV Med. 2008 Jan; 9(1):41-6. 
12. Podlekareva D, Reekie J, Rakhmanova A, Horban A, Mocroft A, Karpov I, et al. Indicators of the use of health care interventions across Europe. In: 15th Conference on Retroviruses and Opportunistic Infections; 2008 Feb 3-6; Boston. Boston: CROI; 2008. Abstract O-138.

13. Lazarus JV, Olsen M, Ditiu L, Matic S. Tuberculosis-HIV co-infection: policy and epidemiology in 25 countries in the WHO European Region. HIV Med. 2008 Apr 10.

14. Lazarus JV, Bollerup A, Matic S. HIV/AIDS in eastern Europe: more than a sexual health crisis. Cent Eur J Public Health. 2006 Jun;14(2):55-8.

15. World Health Organisation. Anti-tuberculosis drug resistance in the world. Report No. 4. The WHO/IUATLD global project on anti-tuberculosis drug resistance surveillance. Geneva: WHO; 2008.
16. Podlekareva D, Mocroft A, Panteleev A, Toibaro J, Rakhmanova A, Riekstina V, et al. Characteristics and clinical outcome of patients with HIV-associated tuberculosis (HIV/TB) in Europe and Argentina. In: 15th Conference on Retroviruses and Opportunistic Infections; 2008 Feb 3-6; Boston. Boston: CROI; 2008. Abstract K-181.

17. Donoghoe MC, Bollerup AR, Lazarus JV, Nielsen S, Matic S. Access to highly active antiretroviral therapy (HAART) for injecting drug users in the WHO European Region 2002-2004. Int J Drug Policy. 2007 Aug;18(4):271-80.

Received April 4, 2008 Accepted June 20, 2008 